\title{
The relation between ambulance transports stratified by heat stroke and air temperature in all 47 prefectures of Japan in August, 2009: ecological study
}

\author{
Nobuyuki Miyatake $\cdot$ Noriko Sakano \\ Shoko Murakami
}

Received: 5 April 2011/Accepted: 7 May 2011/Published online: 26 May 2011

(C) The Japanese Society for Hygiene 2011

\begin{abstract}
Objective Our aim was to investigate the link between ambulance transports stratified by heat stroke and air temperature in August 2009 in Japan.

Methods Monthly observations for ambulance transports stratified by heat stroke in August 2009, in all 47 prefectures of Japan were obtained from the Ministry of Internal Affairs and Communications. Daily air temperature data from the Japan Meteorological Agency in August 2009 for all 47 prefectures in Japan were also used. The effect of high air temperatures on ambulance transports stratified by heat stroke was analyzed in an ecological study.

Results Various air temperature parameters, i.e., the mean of the mean air temperature, mean of the highest air temperature, mean of the lowest air temperature, the highest air temperature, and the lowest air temperature in August 2009 were significantly and positively correlated with ambulance transports stratified by heat stroke (per total number of ambulance transports and per 10,000 persons) in the 47 prefectures of Japan. The correlation coefficient between the mean of the highest air temperature in August 2009 and ambulance transports stratified by heat stroke (per 10000 persons) was the highest among the examined parameters $(r=0.799, p<0.0001)$.

Conclusion Higher air temperatures were closely associated with higher numbers of ambulance transports stratified by heat stroke in August 2009 in Japan.
\end{abstract}

N. Miyatake $(\bowtie) \cdot$ N. Sakano $\cdot$ S. Murakami Department of Hygiene, Faculty of Medicine, Kagawa University, 1750-1, Miki,

Kagawa 761-0793, Japan

e-mail: miyarin@med.kagawa-u.ac.jp
Keywords Heat stroke - Ambulance transports . Air temperature $\cdot$ Japan

\section{Introduction}

More and more attention has been paid to the influence of high air temperatures on human health. Increases in mortality rates and their relation to high air temperatures have been discussed [1, 2]. Global average temperatures are projected to increase by between 1.4 and $5.8^{\circ} \mathrm{C}$ by the end of this century [3]. In addition, it is expected the climatic changes associated with global warming will have a serious impact on human beings $[4,5]$. We have also previously reported that higher air temperatures were associated with the total number of ambulance transports in Takamatsu city [6] and Okayama city [7], Japan. However, the relation between high air temperatures and ambulance transports stratified by heat stroke still remains to be investigated in Japan.

Therefore, in this study, we evaluated the link between ambulance transports stratified by heat stroke and parameters of air temperature in August 2009 in all 47 prefectures of Japan, and we clarified the effect of higher air temperatures on heat stroke in Japan by carrying out an ecological study.

\section{Methods}

Ambulance data

Monthly incidence data of ambulance transports stratified by heat stroke were obtained from the Ministry of Internal Affairs and Communications in August 2009 for all 47 prefectures of Japan [8]. In addition, we also obtained the data for the total number of ambulance transports [8] and 
Table 1 Profile of 47 prefectures in Japan

\begin{tabular}{|c|c|c|c|}
\hline & Mean $\pm \mathrm{SD}$ & Minimum & Maximum \\
\hline Number of prefectures & 47 & & \\
\hline Population $(10,000$ persons $)$ & $271.7 \pm 263.8$ & 60.0 & 1284.0 \\
\hline Total number of ambulance transports (persons) & $8685.6 \pm 9526.6$ & 1685.0 & 48862.0 \\
\hline Ambulance transports stratified by heat stroke (persons) & $138.2 \pm 119.7$ & 16.0 & 590.0 \\
\hline Heat stroke per total number of ambulance transports: $(\%)$ & $1.9 \pm 0.9$ & 0.4 & 4.0 \\
\hline Heat stroke (per 10,000 persons) & $0.59 \pm 0.30$ & 0.12 & 1.38 \\
\hline Mean of the mean air temperature $\left({ }^{\circ} \mathrm{C}\right)$ & $26.2 \pm 1.9$ & 21.5 & 29.5 \\
\hline Mean of the highest air temperature $\left({ }^{\circ} \mathrm{C}\right)$ & $30.5 \pm 2.0$ & 25.3 & 33.8 \\
\hline Mean of the lowest air temperature $\left({ }^{\circ} \mathrm{C}\right)$ & $23.0 \pm 1.9$ & 18.6 & 27.3 \\
\hline The highest air temperature $\left({ }^{\circ} \mathrm{C}\right)$ & $34.5 \pm 1.6$ & 30.9 & 37.8 \\
\hline The lowest air temperature $\left({ }^{\circ} \mathrm{C}\right)$ & $18.2 \pm 2.5$ & 11.8 & 25.6 \\
\hline
\end{tabular}

Table 2 Simple correlation analysis between numbers of ambulance transports stratified by heat stroke and air temperature parameters in 47 prefectures

\begin{tabular}{|c|c|c|c|c|}
\hline & \multicolumn{4}{|c|}{ Ambulance transports stratified by heat stroke } \\
\hline & \multicolumn{2}{|c|}{ Per total number of ambulance transports $(\%)$} & \multicolumn{2}{|c|}{ Per 10,000 persons } \\
\hline & $r$ & $p$ & $r$ & $p$ \\
\hline Mean of the mean air temperature $\left({ }^{\circ} \mathrm{C}\right)$ & 0.686 & $<0.0001$ & 0.797 & $<0.0001$ \\
\hline Mean of the highest air temperature $\left({ }^{\circ} \mathrm{C}\right)$ & 0.708 & $<0.0001$ & 0.799 & $<0.0001$ \\
\hline Mean of the lowest air temperature $\left({ }^{\circ} \mathrm{C}\right)$ & 0.609 & $<0.0001$ & 0.739 & $<0.0001$ \\
\hline The highest air temperature $\left({ }^{\circ} \mathrm{C}\right)$ & 0.713 & $<0.0001$ & 0.673 & $<0.0001$ \\
\hline The lowest air temperature $\left({ }^{\circ} \mathrm{C}\right)$ & 0.548 & $<0.0001$ & 0.703 & $<0.0001$ \\
\hline
\end{tabular}

Values in bold indicate significance

the population data for the 47 prefectures in 2009 from the Ministry of Internal Affairs and Communications [9]. The number of ambulance transports stratified by heat stroke (per total number of ambulance transports (\%) and per 10,000 persons) was used for analysis.

\section{Temperatures}

Daily air temperatures in the 47 prefectures of Japan for the required period (August 2009) were obtained from the Japan Meteorological Agency [10]. The mean of the mean air temperature, mean of the highest air temperature, mean of the lowest air temperature, the highest air temperature, and the lowest air temperature in August 2009 in the 47 prefectures of Japan were used for analysis.

\section{Statistical analysis}

Simple correlation analysis was used to test the significance of the linear relationship among continuous variables: $p<0.05$ was considered to be statistically significant. In addition, the Joinpoint Regression Program $[11,12]$ was also used to investigate the threshold, where different lines of ambulance transports stratified by heat stroke were connected together.

\section{Results}

Relevant profiles of the 47 prefectures in Japan are summarized in Table 1. The number of ambulance transports, stratified by heat stroke, was $138.2 \pm 119.7$ persons, $1.9 \pm 0.9$ (per total number of ambulance transports: \%), and $0.59 \pm 0.30$ (per 10,000 persons) in the 47 prefectures. The mean of the mean air temperature was $26.2 \pm 1.9^{\circ} \mathrm{C}$ (range 21.5-29.5).

We investigated the relationship between ambulance transports stratified by heat stroke and various parameters of air temperature (Table 2). Ambulance transports stratified by heat stroke were significantly and positively correlated with various parameters of air temperature, i.e., the mean of the mean air temperature, mean of the highest air temperature, mean of the lowest air temperature, the highest air temperature,and the lowest air temperature in August 2009 in Japan. The correlation coefficient between ambulance transports stratified by heat stroke (per 10,000 


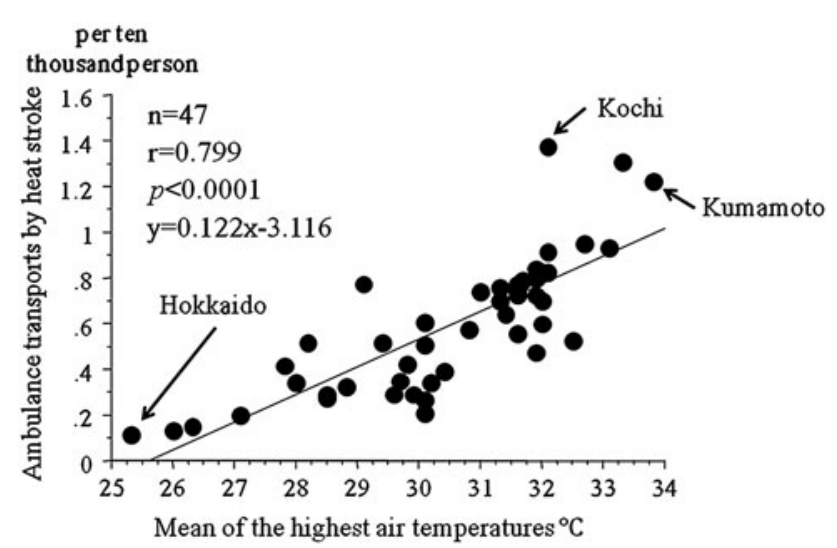

Fig. 1 Simple correlation analysis between number of ambulance transports stratified by heat stroke (per 10,000 persons) and the mean of the highest air temperature in the 47 prefectures of Japan in August 2009

persons) and the mean of the highest air temperature was the highest among the examined parameters $(r=0.799$, $p<0.0001$ ) (Fig. 1). On using the Joinpoint Regression Program, we could not find the change points of ambulance transports stratified by heat stroke in mean of the highest air temperatures. The number of ambulance transports stratified by heat stroke (per 10,000 persons) and the mean of the highest air temperature were lowest in Hokkaido, which is located in the most northern part of Japan. The number of ambulance transports stratified by heat stroke (per 10,000 persons) was the highest in Kochi, which is located on Shikoku Island, and the mean of the highest air temperature was highest in Kumamoto, which is located on Kyushu Island in Japan (Fig. 1).

\section{Discussion}

The main finding of this ecological study in the 47 prefectures of Japan was that the number of ambulance transports, stratified by heat stroke, was positively correlated with higher air temperatures.

The relation between high air temperatures and heat stroke in Japan has been reported in some studies [13-16]. Qiu et al. [13] reported that an unusually hot spell in 1999 was followed by a high mortality rate in Hokkaido, Japan. Bai et al. [14] reported that the number of unusual deaths in the summer of 1994 in Osaka, Japan, was greater than that in the previous year. Piver et al. [15] reported that heat stroke was associated with prolonged exposures to the higher air temperatures that usually occur in the summer months of July and August in 1980-1995 in Tokyo. Nakai et al. [16] investigated heat-related deaths in Japan from 1968 through 1994 and showed that heat-related deaths were most likely to occur on days with a peak daily air temperature above $38^{\circ} \mathrm{C}$.
They reported that the incidence of heat-related deaths showed an exponential dependence on the number of hot days [16]. In addition, we have also shown that higher air temperatures were closely associated with the total number of ambulance transports, by using monthly data in Takamatsu city and Okayama city, Japan $[6,7]$. In the present study, in August 2009 in Japan, as in the previous studies, we also noted a close link between the number of ambulance transports and higher air temperatures. Furthermore, the slope of the regression line (change in the highest air temperature versus change in number of ambulance transports stratified by heat stroke) in Japan was 0.122 (Fig. 1). Accordingly, we found that a $1^{\circ} \mathrm{C}$ increase in the mean of the highest air temperature in Japan corresponded to a 0.122 times per 10,000 person increase in the number of ambulance transports stratified by heat stroke in Japan. However, we could not find the threshold of air temperature for ambulance transports stratified by heat stroke in this analysis. Global warming has become a public health challenge worldwide [5]. The above findings, taken together, suggest that it is reasonable that we need to deal with high air temperatures in summer in Japan, e.g., by innovations in the use of thermal energy in cities, preparation of the ambulance transport system, and individual coping with high air temperatures.

Potential limitations remain in this study. First, this was an ecological study. The link between numbers of ambulance transports stratified by heat stroke and air temperature, which was noted in this study, may not apply to the link among individuals. Second, daily data for ambulance transports stratified by heat stroke could not be obtained in this study. Therefore, we could not accurately evaluate the link between ambulance transports stratified by heat stroke and high air temperatures. Further studies are urgently required to prove such a link.

Acknowledgments This research was supported in part by Research Grants from FUKUTAKE Science \& Culture Foundation, Japan.

\section{References}

1. Nakai S. Number of deaths from heat stroke and meteorological condition-a survey of the last 21 years in Japan. Jpn J Biometeor. 1993;30:169-77 (in Japanese).

2. Kalkstein LS, Greene JS. An evaluation of climate/mortality relationships in large US cities and the possible impacts of a climate change. Environ Health Perspect. 1997;105:84-93.

3. Intergovernmental Panel on Climate Change. Climate Change 2001. The scientific basis: contribution of Working Group 1 to the third assessment report 1-944. Cambridge, UK: Cambridge University Press; 2001.

4. Loevinsohn ME. Climatic warming and increased malaria incidence in Rwanda. Lancet. 1994;343:714-8.

5. Kalkstein LS, Smoyer KE. The impact of climate change on human health: some international implications. Experientia. 1993;49:969-79. 
6. Miyatake N, Nakao M, Sakano N, Suna S, Suzue T, Hirao T. Higher temperatures were associated with ambulance transports in Takamatsu area, Japan. J Environ Prot. 2011;2:72-5.

7. Sakano N, Miyatake N, Suna S, Suzue T, Hirao T, Ogino K. The relationship between high temperatures and ambulance transports in Okayama city, Japan. J Prev Med. 2011;6:17-20 (in Japanese).

8. Ministry of Internal Affairs and Communications. http://www. fdma.go.jp/pdf/2009/1002/02_betten1.pdf.

9. Ministry of Internal Affairs and Communications. http://www. e-stat.go.jp/SG1/estat/List.do?bid $=000001025238 \&$ cycode $=0$.

10. Japan Meteorological Agency. http://www.data.jma.go.jp/obd/ stats/etrn/index.php.

11. National Cancer Institute Joinpoint Regression Program, version 3.4.3. http://srab.cancer.gov/joinpoint/.

12. Sakano N, Miyatake N, Murakami S, Suzue T, Hirao T, Ogino $\mathrm{K}$. Changes in temperatures in Okayama area compared with different urbanization areas, Japan. J Environ Prot. 2011;2:162-7.

13. Qiu D, Tanihata T, Aoyama H, Fujita T, Inaba Y, Minowa M. Relationship between a high mortality rate and extreme heat during the summer of 1999 in Hokkaido Prefecture, Japan. J Epidemiol. 2002;12:254-7.

14. Bai H, Islam MN, Kuroki H, Honda K, Wakasugi C. Deaths due to heat waves during the summer of 1994 in Osaka Prefecture, Japan. Nihon Hoigaku Zasshi. 1995;49:265-74. (in Japanese).

15. Piver WT, Ando M, Ye F, Portier CJ. Temperature and air pollution as risk factors for heat stroke in Tokyo, July and August 1980-1995. Environ Health Perspect. 1999;107:911-6.

16. Nakai S, Itoh T, Morimoto T. Deaths from heat-stroke in Japan: 1968-1994. Int J Biometeorol. 1999;43:124-7. 